\title{
Resistance to Fusarium Head Blight and Deoxynivalenol Accumulation in Virginia Barley
}

Piyum A. Khatibi, Department of Plant Pathology, Physiology, and Weed Science, and Greg Berger, Department of Crop and Soil Environmental Sciences, Virginia Tech, Blacksburg 24061; Shuyu Liu, Texas AgriLife Research, Texas A \& M University, Amarillo 79106; and Wynse S. Brooks, Department of Crop and Soil Environmental Sciences, Carl A. Griffey, Department of Crop and Soil Environmental Sciences, and David G. Schmale, III, Department of Plant Pathology, Physiology, and Weed Science, Virginia Tech

\begin{abstract}
Khatibi, P. A., Berger, G., Liu, S., Brooks, W. S., Griffey, C. A., and Schmale, D. G., III. 2012. Resistance to Fusarium head blight and deoxynivalenol accumulation in Virginia barley. Plant Dis. 96:279-284.

Fusarium head blight (FHB), caused by the fungal plant pathogen Fusarium graminearum (teleomorph Gibberella zeae), is a devastating disease of barley (Hordeum vulgare) in the United States. Recent epidemics of FHB in the mid-Atlantic region have underscored the need to develop new commercial varieties of barley that are resistant to FHB and restrict accumulation of the mycotoxin deoxynivalenol (DON). FHB incidence, FHB index, and DON levels of Virginia hulled and hulless barley genotypes were evaluated over five years (2006 to 2010) in FHB nurseries in Virginia. FHB incidence ranged from $22.5 \%$ (2010) to $80.1 \%$ (2008), and mean DON levels ranged from $0.5 \pm 0.4$

role in determining FHB resistance in 2006 to 2009. DON levels were significantly different among barley genotypes in 2007, 2008, and 2009. FHB incidence was positively correlated with FHB index in all 5 years studied. In 2006 and 2010, FHB incidence and index were positively correlated with DON. Early spike emergence resulted in higher FHB incidence and index in 2007, 2008, and 2010. This preliminary work has identified some promising hulled and hulless barley genotypes for targeted breeding and commercialization efforts in FHB nurseries in the future; 'Eve' (hulless) and 'Thoroughbred' (hulled) ranked among the most FHB resistant genotypes.
\end{abstract} (2008) to $2.4 \pm 2.1 \mathrm{ppm}$ (2010). Barley genotype played a significant
One of the most important diseases of barley (Hordeum vulgare L.) in the United States is Fusarium head blight (FHB), caused primarily by the fungal plant pathogen Fusarium graminearum Schwabe (teleomorph Gibberella zeae) (12). FHB can cause considerable reductions in yield and grain quality when the invading fungus releases cell-wall-degrading enzymes and mycotoxins $(15,24) . F$. graminearum produces a dangerous mycotoxin called deoxynivalenol (DON) that is released during infection (23). DON is a sesquiterpene epoxide that inhibits protein synthesis in eukaryotes (19) and may cause vomiting and feed refusal in domestic animals (26). From 1998 to 2000, barley contaminated with DON resulted in an economic loss of an estimated \$136 million (32).

Since the 1990s, FHB screening programs have been set up to evaluate disease resistance and DON levels in barley (29). Disease levels are assessed by measuring FHB severity (average percentage of diseased spikelets per diseased spike), FHB incidence (the percentage of diseased heads out of all heads sampled), and FHB index (average percentage of diseased spikelets out of all heads sampled) (25). There are two primary types of resistance to FHB and DON in barley: type I, resistance to initial infection, measured by incidence (28); and type II, resistance to the movement and spread of the fungus (28). Barley has natural type II resistance, where disease spreading to adjacent spikelets is prevented by the rachis node and rachilla, although movement can still proceed through the phloem and rachis surface (14).

Type I resistance in barley may be determined by measuring FHB incidence and FHB index and is critical to reducing FHB; however, FHB resistance is controlled by multiple genes (1), and coupling disease resistance with suitable agronomic and quality

Corresponding author: D. G. Schmale, III, E-mail: dschmale@ vt.edu

Accepted for publication 28 September 2011.

http://dx.doi.org/10.1094/PDIS-07-11-0551

(C) 2012 The American Phytopathological Society traits is a challenge (9). For example, in a cross between 'Chevron' and 'M69' barley, quantitative trait loci (QTLs) linked to FHB resistance were identified across seven chromosomes (10). In all, 10 QTLs were associated with FHB resistance, 11 QTLs were linked to low DON accumulation, and 4 QTLs were coupled to kernel discoloration (10). In particular, the chromosome $2(2 \mathrm{H})$ bin10 region has been labeled as a major QTL for FHB resistance (3). Chromosome 7H (10) and chromosome 6H (4) have been associated with low DON accumulation and low kernel discoloration, respectively (1). There is evidence that FHB severity and DON levels in cereals are negatively correlated with plant height, days to heading, spike angle, and spike density (33).

Epidemics of FHB in the mid-Atlantic (20) and southeast (8) regions of the United States have underscored the need to develop new commercial varieties of barley that are resistant to FHB and accumulate low levels of DON. An increased knowledge of these traits will directly benefit growers and producers of barley in the eastern United States. Here, we present the results of a 5-year research effort focused on identifying promising winter hulled and hulless barley genotypes that are resistant to FHB and accumulate low levels of DON. In contrast to hulless barley, the hulled barley genotype has a hull that is attached to the seed epidermis (31). We hypothesized that (i) FHB resistance is associated with reduced DON accumulation in barley and (ii) specific barley genotypes show consistent year-to-year FHB resistance and reduced DON accumulation. The specific objective of our work is to identify genotypes of winter barley in Virginia that are resistant to FHB and reduced in their ability to accumulate DON. These genotypes could be used for targeted breeding and commercialization efforts in the future. There is currently little information on FHB and DON in winter barley in the United States. To our knowledge, this is the first study to evaluate FHB resistance and DON accumulation in hulled and hulless winter barley genotypes grown east of the Mississippi river.

\section{Materials and Methods}

DON and FHB assessments. In all, 13 (2006) to 32 (2008) hulless and 22 (2009) to 37 (2010) hulled genotypes were planted 
in a randomized complete block with two replications in a mistirrigated nursery at Blacksburg, VA over 5 years (2006 to 2010). Barley plants in the scab nursery were grown in two-row plots with dimensions of $1.22 \mathrm{~m}$ long and $0.31 \mathrm{~m}$ between each row and were inoculated with aqueous suspensions of $F$. graminearum macroconidia. Isolate ID, mycotoxin genotype, and source location of $F$. graminearum isolates used to infect barley lines or cultivars from 2006 to 2010 are listed in Table 1. All isolates were collected from wheat heads in Virginia showing symptoms of FHB. Heads were plated on Fusarium selective medium (FSM), and isolates of $F$. graminearum were subcultured on quarter-strength potato dextrose agar (PDA). FSM consisted of agar at $15 \mathrm{~g} /$ liter (Fisher Scientific, Fair Lawn, NJ) bacto peptone at $15 \mathrm{~g} /$ liter (BD Biosciences, Sparks, MD), potassium phosphate monobasic at $1.0 \mathrm{~g} /$ liter (Fisher Scientific), magnesium sulfate at $0.5 \mathrm{~g} /$ liter (Fisher Scientific), Terrachlor fungicide at $1 \mathrm{~g} /$ liter (Crompton, Middlebury, CT), streptomycin at $1 \mathrm{~g} /$ liter (Fisher Scientific), and neomycin at 350 $\mathrm{mg} /$ liter (Sigma-Aldrich, St. Louis). PDA consisted of potato dextrose broth at $6 \mathrm{~g} /$ liter (BD Biosciences) and agar at $15 \mathrm{~g} / \mathrm{liter}$ (Fisher Scientific). Culture stocks were stored in $20 \%$ glycerol at $-80^{\circ} \mathrm{C}$. To initiate FHB, barley heads were spray inoculated with macroconidia $(50,000$ spores $/ \mathrm{ml}$, harvested from agar plates and quantified using a hemacytometer) at $50 \%$ anthesis (flowering date [FD]), as described previously (5). Following inoculation, overhead mist irrigation was applied at 1-h intervals from 8:00 to 9:00 a.m. and from 4:00 to 5:00 p.m. daily for 3 weeks, except during precipitation events, as described previously (5). Plots were then rated for FHB incidence (percentage of infected heads among 10 random heads per plot), and FHB severity (number of infected spikelets divided by the total number of spikelets for 10 diseased heads per plot). FHB severity data was used in the calculation of FHB index (FHB incidence $\times$ FHB severity/100).

Quantification of DON from barley samples. Extraction and quantification of DON from barley samples was conducted following standard protocols $(13,17,30)$. A research-plot combine harvested all genotypes on the same day in the summer of each year.

Table 1. Isolate, mycotoxin genotype, and source location of Fusarium graminearum isolates used to infect barley lines or cultivars from 2006 to $2010^{\mathrm{a}}$

\begin{tabular}{|c|c|c|c|}
\hline Year & 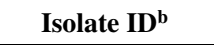 & TRI3/TRII2 genotype ${ }^{\mathrm{c}}$ & Location \\
\hline 2006 & Mixed VA strains & Unknown & Blacksburg, VA \\
\hline 2007 & Mixed VA strains & Unknown & Blacksburg, VA \\
\hline \multirow[t]{2}{*}{2008} & VA13n4 & 3-ADON & \\
\hline & VA8n12 & $15-A D O N$ & Riner, VA \\
\hline \multirow[t]{2}{*}{2009} & VA8n12 & 15-ADON & \\
\hline & $\begin{array}{l}\text { VA11n9 } \\
\text { VA12n18 }\end{array}$ & $\begin{array}{l}3-\mathrm{ADON} \\
15-\mathrm{ADON}\end{array}$ & Riner, VA \\
\hline \multirow[t]{3}{*}{2010} & VA8n12 & $15-\mathrm{ADON}$ & \\
\hline & VA11n9 & 3-ADON & \\
\hline & VA12n18 & 15-ADON & Riner, VA \\
\hline
\end{tabular}

a Aqueous suspensions of 50,000 spores/ml were sprayed on Virginia winter barley plants at $50 \%$ anthesis in a mist-irrigated nursery at Blacksburg, VA.

${ }^{b}$ Macroconidia used for spraying in Fusarium head blight (FHB) nursery were derived from Fusarium graminearum isolates that were collected from wheat heads in Virginia showing symptoms of FHB.

c 3-ADON = 3-acetyl deoxynivalenol and 15-adon = 15-acetyl deoxynivalenol.
At the time of harvest, all grain was at maturity (16\% or less moisture content). Throughout threshing, the blower was kept at a low setting to reduce the loss of grain, especially kernels of low weight. The grain was then cleaned on a screen cleaner without air that allows grain to pass through and remove plant debris. Kernel samples of $100 \mathrm{~g}$ were run through a grinding mill and then passed through a number 20 sieve to maintain a uniform particle size. Sieved samples were weighed to $1 \mathrm{~g}$ and added to $4 \mathrm{ml}$ of solvent (86\% acetonitrile and $14 \%$ water) and placed on a shaker at 200 rpm for $1 \mathrm{~h}$. The solvent containing DON was then passed through a clean-up column composed of a 1-g mixture of C18 (VWR, Radnor, PA) and aluminum oxide (Sigma-Aldrich) at a 1:3 ratio. A 1$\mathrm{ml}$ aliquot of eluent was transferred to a glass test tube and evaporated to dryness using a nitrogen evaporator set at $55^{\circ} \mathrm{C}$. Dried samples were then silyated with $50 \mu \mathrm{l}$ of $N$-trimethylsilylimidazole. After $15 \mathrm{~min}, 250 \mu \mathrm{l}$ of isooctane was added to each tube followed by $250 \mu \mathrm{l}$ of water to quench the reaction. Samples were vortexed for $30 \mathrm{~s}$ and the supernatant was removed and transferred to chromatography vials for quantification using gas chromatographymass spectrometry.

In 2007, 2008, and 2009, DON was quantified from two replicates of each barley genotype. In 2006 and 2010, DON was quantified from the composite of two replicates. DON quantification was performed using an Agilent 6890/5975 system operating in selected ion-monitoring mode. This mode detected the DON target ion at a mass/charge ratio of 235 , with reference ions at 259 and 422. The initial column temperature was held at $150^{\circ} \mathrm{C}$ for $1 \mathrm{~min}$, increased to $280^{\circ} \mathrm{C}$ at a rate of $30^{\circ} \mathrm{C} / \mathrm{min}$, and held constant for 5 min. The injection temperature was set at $300^{\circ} \mathrm{C}$ and the flow rate of the column was $1 \mathrm{ml} / \mathrm{min}$. DON was quantified using a linear regression model for appropriate trichothecene standards (Biopure, Austria) of $0.01,0.1,1$, and $10 \mathrm{ppm}$.

Statistical analyses. PROC GLIMMIX in SAS (version 9.2; SAS Institute, Cary, NC) was used to test for significant differences across years in FD, FHB incidence, FHB index, and DON concentration. Tukey-Kramer honestly significant difference was used to test for all pairwise comparisons between factors. PROC CORR in SAS (version 9.2; SAS Institute) was used to test for correlations between FHB incidence, FHB index, DON, and FD. A subset of 10 ( 7 hulled and 3 hulless) genotypes was evaluated during all 5 years of the study and was analyzed to determine the stability of genotypes for FHB resistance across years.

\section{Results}

Analysis of Virginia winter barley genotypes. From 2006 to 2010, mean DON levels in Virginia barley genotypes ranged from 0.5 to $2.4 \mathrm{ppm}$ and mean FD ranged from 114.8 to 124.8 days (Table 2). Mean FHB incidence and index were highest in 2008 at 80.1 and $38.0 \%$, respectively, but had the lowest mean DON concentration at $0.5 \mathrm{ppm}$ (Table 2). The lowest FHB incidence occurred in 2010, with an average rating of $22.5 \%$ (Table 2). Mean FHB index was the lowest in 2006 at $4.8 \%$ (Table 2).

To determine significant differences within each year for FD, incidence, index, and DON, the mean square errors were calculated from an analysis of variance and significant differences were determined (Table 3). Each year from 2006 to 2009, there were significant differences among genotypes for FD $(P \leq 0.01)$, FHB incidence $(P \leq 0.01)$, and FHB index $(P \leq 0.05)$ (Table 3$)$. In 2010, significant differences among genotypes were observed for FD $(P$

Table 2. Grand means \pm standard error of the means for Fusarium head blight (FHB) incidence, FHB index, deoxynivalenol (DON) concentration (ppm), and flowering date (FD) for all Virginia winter barley genotypes studied from 2006 to 2010

\begin{tabular}{|c|c|c|c|c|c|}
\hline Parameters & 2006 & 2007 & 2008 & 2009 & 2010 \\
\hline Number of genotypes & 39 & 49 & 64 & 52 & 63 \\
\hline FHB incidence $(\%)$ & $59.4 \pm 1.7$ & $55.3 \pm 2.3$ & $80.1 \pm 2.6$ & $25.1 \pm 2.3$ & $22.5 \pm 2.4$ \\
\hline FHB index $(\%)$ & $4.8 \pm 0.3$ & $11.9 \pm 0.9$ & $38.0 \pm 2.8$ & $5.6 \pm 0.8$ & $5.3 \pm 0.8$ \\
\hline $\mathrm{DON}(\mathrm{ppm})$ & $2.1 \pm 0.4$ & $1.3 \pm 0.1$ & $0.5 \pm 0.1$ & $1.5 \pm 0.2$ & $2.4 \pm 0.3$ \\
\hline FD (days from 1 January) ${ }^{\mathrm{a}}$ & $114.8 \pm 0.5$ & $124.8 \pm 0.6$ & $117.3 \pm 0.4$ & $115.0 \pm 0.2$ & $117.8 \pm 0.5$ \\
\hline
\end{tabular}

a Barley heads at $50 \%$ anthesis. 
$\leq 0.001)$ and FHB incidence $(P \leq 0.001)$ but not FHB index $(P>$ 0.05 ) (Table 3). DON levels from 2007 to 2009 showed significant differences among barley genotypes $(P \leq 0.05$; Table 3$)$. Significant differences were observed among replicates in 2007 (incidence and index), 2008 (DON), and 2009 (incidence and index) (Table 3).

Correlations between FHB incidence, FHB index, and DON. Correlations were performed to investigate whether there was an association between FHB and DON levels in grain (Table 4). For every year during the 5-year study, there was a significant positive correlation between FHB incidence and index (Table 4). FHB incidence and index were positively correlated with DON levels in 2006 ( $r=0.44, P \leq 0.01$ and $r=0.67, P \leq 0.001$, respectively) and in 2010 ( $r=0.82, P \leq 0.001$ and $r=0.91, P \leq 0.001$, respectively) (Table 4). However, from 2007 to 2009, DON levels were not correlated with FHB incidence or index (Table 4). In 2007, 2008, and 2010, there was a significant negative association between FD with FHB incidence and index, with correlation coefficients ranging from -0.43 to -0.83 ( $P \leq 0.01$; Table 4$)$. In 2006 and 2009, there was no association between FD with FHB incidence and index (Table 4).

Analysis of individual genotypes across all 5 years. A subset of 10 ( 7 hulled and 3 hulless) genotypes was analyzed to determine stability of genotypes for FHB resistance across years. Significant differences $(P \leq 0.001)$ for year, genotypes, and genotype $\times$ year interactions were observed for FD, FHB incidence, and FHB index (Table 5). Significant differences $(P \leq 0.05)$ for genotypes and genotype $\times$ year interaction were observed for DON concentration.

The hulless barley 'Eve' was ranked in the top three for lowest FHB incidence (ranging from $7.5 \%$ in 2010 to $45 \%$ in 2007; Table 6). Eve was ranked in the top four for lowest FHB index in 2006, 2008, 2009, and 2010 and had the lowest DON accumulation levels in years 2006, 2009, and 2010 (Table 6). The hulled barley 'Thoroughbred' was consistently resistant to FHB from 2006 to 2009, with rankings in the top four for lowest FHB incidence (ranging from $7.5 \%$ in 2009 to $65 \%$ in 2008) and index (ranging from $3.5 \%$ in 2006 to $12.3 \%$ in 2008) (Table 6). Hulled barley 'Callao' was consistently susceptible to FHB, with incidence ratings that were steadily in the bottom four each year (ranging from 20\% in 2009 to $95 \%$ in 2008; Table 6). Callao also demonstrated consistently high FHB index ratings (Table 6). Callao accumulated low levels of DON in 2008 and 2010, however, in the other 3 years, DON levels were high, with concentrations ranging from $1.4 \mathrm{ppm}$ (ranked 7th) to $2.3 \mathrm{ppm}$ (ranked 10th) (Table 6).

\section{Discussion}

This study reports resistance to FHB and DON accumulation in Virginia winter hulled and hulless barley genotypes in FHB nurseries across 5 years (2006 to 2010) and illustrates the natural year-toyear variability that is associated with field experiments (Table 2). To our knowledge, this is the first study to evaluate FHB resistance and DON accumulation in hulled and hulless winter barley genotypes grown east of the Mississippi river. This preliminary work has identified some promising hulled and hulless barley genotypes for targeted breeding and commercialization efforts in FHB nurseries in the future. The FHB and DON assessment techniques reported in this work should be of value to others working with FHB nurseries in barley and other small grains.

Susceptibility and resistance of Virginia barley genotypes to FHB and DON were determined by evaluating the effects of FHB incidence, FHB index, DON, and FD. Barley genotypes were

Table 4. Correlation coefficients for flowering date (FD), Fusarium head blight (FHB) incidence, FHB index, and deoxynivalenol (DON) concentration from 2006 to $2010^{\mathrm{a}}$

\begin{tabular}{|c|c|c|c|}
\hline Year $^{b}$ & FHB incidence & FHB index & DON \\
\hline \multicolumn{4}{|l|}{2006} \\
\hline $\mathrm{FD}$ & 0.21 & 0.26 & $0.71 * * *$ \\
\hline FHB incidence & $\ldots$ & $0.78 * * *$ & $0.44 * *$ \\
\hline FHB index & $\ldots$ & $\ldots$ & $0.67 * * *$ \\
\hline \multicolumn{4}{|l|}{2007} \\
\hline FD & $-0.43 * *$ & $-0.54 * * *$ & 0.12 \\
\hline FHB incidence & $\ldots$ & $0.74 * * *$ & -0.12 \\
\hline FHB index & $\ldots$ & $\ldots$ & -0.04 \\
\hline \multicolumn{4}{|l|}{2008} \\
\hline FD & $-0.60 * * *$ & $-0.63 * * *$ & 0.05 \\
\hline FHB incidence & $\ldots$ & $0.83 * * *$ & -0.10 \\
\hline FHB index & $\ldots$ & $\ldots$ & -0.18 \\
\hline \multicolumn{4}{|l|}{2009} \\
\hline FD & -0.10 & -0.03 & 0.08 \\
\hline FHB incidence & $\ldots$ & $0.94 * * *$ & 0.10 \\
\hline FHB index & $\ldots$ & $\ldots$ & 0.07 \\
\hline \multicolumn{4}{|l|}{2010} \\
\hline FD & $-0.83 * * *$ & $-0.69 * * *$ & $-0.68 * * *$ \\
\hline FHB incidence & $\ldots$ & $0.89 * * *$ & $0.82 * * *$ \\
\hline FHB index & $\ldots$ & $\ldots$ & $0.91 * * *$ \\
\hline
\end{tabular}

a Asterisks *,**, and $* * *$ indicate significance at $P \leq 0.05,0.01$, and 0.001 , respectively.

${ }^{\mathrm{b}}$ Flowering date $(\mathrm{FD})=$ days from 1 January.

Table 3. Mean square errors from analysis of variance for lines or cultivars within years and the respective degrees of freedom (df) ${ }^{\mathrm{a}}$

\begin{tabular}{|c|c|c|c|c|c|}
\hline Effect & df & $\mathbf{F D}^{\mathbf{b}}$ & Incidence & Index & DON $^{c}$ \\
\hline \multicolumn{6}{|l|}{2006} \\
\hline Rep & 1 & 0.63 & 370.65 & 3.06 & $\ldots$ \\
\hline Genotype & 38 & $17.00 * * *$ & $221.65 * * *$ & $8.85^{*}$ & $\ldots$ \\
\hline Residual & 38 & 1.79 & 123.14 & 4.56 & $\ldots$ \\
\hline \multicolumn{6}{|l|}{2007} \\
\hline Rep & 1 & 0.66 & $2158.43 * *$ & $340.04 * *$ & 1.74 \\
\hline Genotype & 48 & $30.22 * *$ & $521.42 * *$ & $78.40 * *$ & $0.86^{*}$ \\
\hline Residual & 48 & 10.95 & 242.52 & 46.39 & 0.53 \\
\hline \multicolumn{6}{|l|}{2008} \\
\hline Rep & 1 & 9.02 & 0.00 & 64.05 & $0.79 *$ \\
\hline Genotype & 63 & $23.21 * * *$ & 832.46 *** & $999.18 * * *$ & $0.33 * * *$ \\
\hline Residual & 63 & 8.76 & 232.53 & 256.20 & 0.12 \\
\hline \multicolumn{6}{|l|}{2009} \\
\hline Rep & 1 & 0.16 & $1144.53 * * *$ & $272.20 * * *$ & 1.39 \\
\hline Genotype & 51 & $2.49 * * *$ & $535.46 * * *$ & $68.92 * * *$ & $3.43 * *$ \\
\hline Residual & 51 & 0.33 & 100.84 & 18.33 & 1.74 \\
\hline \multicolumn{6}{|l|}{2010} \\
\hline Rep & 1 & 0.02 & 5.07 & 0.55 & $\ldots$ \\
\hline Genotype & 62 & $26.63 * * *$ & $709.35 * * *$ & 79.32 & $\ldots$ \\
\hline Residual & 62 & 2.50 & 253.34 & 55.47 & $\ldots$ \\
\hline
\end{tabular}

a Asterisks *,**, and $* * *$ indicate significance at $P \leq 0.05,0.01$, and 0.001 , respectively.

${ }^{\mathrm{b}}$ Flowering date $(\mathrm{FD})=$ days from 1 January.

c Deoxynivalenol (DON) for 2006 and 2010 was omitted from the analysis due to lack of replication. 
sprayed at $50 \%$ anthesis with aqueous suspensions of macroconidia $(50,000$ spores $/ \mathrm{ml})$ in order to get sufficient disease in the field necessary to evaluate disease resistance. Spraying at 50\% anthesis with 50,000 spores $/ \mathrm{ml}$ is not uncommon and has been used previously to measure resistance in barley and wheat $(5,7,27)$. Earlier work has shown that susceptibility to FHB is achievable through all stages of grain development (11). Our analysis showed that barley genotypes played a significant role in determining the level of disease and DON accumulation in all years of the study (Table 3 ), illustrating the impact individual barley lines or cultivars and their respective genetics and morphology have on the level of disease. In previous reports, resistant cultivars of wheat (Triticum aestivum L.)

Table 5. Mean square errors from analysis of variance for years, genotypes, and genotype $\times$ year interaction for 10 selected barley genotypes $(7$ hulled and 3 hulless) included in all 5 years of the study ${ }^{\mathrm{a}}$

\begin{tabular}{lcccccc}
\hline Effect & $\mathbf{d f}^{\mathbf{b}}$ & $\mathbf{F D}^{\mathbf{c}}$ & Incidence & Index $^{*}$ & $\mathbf{d f}^{\mathbf{b}}$ & DON $^{\mathbf{d}}$ \\
\hline Year & 4 & $317.79^{* * *}$ & $655.28^{* * *}$ & $315.28^{* * *}$ & 2 & 1.42 \\
Year (Rep) & 5 & 3.55 & 6.24 & 6.60 & 3 & 0.52 \\
Genotype & 9 & $46.93^{* * *}$ & $1,298.74^{* * *}$ & $470.62^{* * *}$ & 9 & $2.70^{*}$ \\
Genotype $\times$ year & 36 & $14.59^{* * *}$ & $701.03^{* * *}$ & $435.27^{* * *}$ & 18 & $3.54^{* *}$ \\
Residual & 45 & 3.55 & 130.79 & 52.76 & 27 & 1.18 \\
\hline
\end{tabular}

a Asterisks $* * *$, and $* * *$ indicate significance at $P \leq 0.05,0.01$, and 0.001 , respectively.

${ }^{\mathrm{b}}$ Degrees of freedom.

${ }^{\mathrm{c}}$ Flowering date $(\mathrm{FD})=$ days from 1 January.

${ }^{\mathrm{d}}$ Deoxynivalenol (DON) for 2006 and 2010 was omitted from the analysis due to lack of replication.

Table 6. Means and rank, separated by year, for 10 selected barley genotypes ( 7 hulled and 3 hulless) included in all 5 years of the study

\begin{tabular}{|c|c|c|c|c|c|c|c|c|c|c|}
\hline Line $^{a}$ & 2006 & Rank & 2007 & Rank & 2008 & Rank & 2009 & Rank & 2010 & Rank \\
\hline \multicolumn{11}{|l|}{$\mathrm{FD}^{\mathrm{b}}$} \\
\hline Barsoy & 110.0 & 1 & 118.0 & 1 & 112.5 & 2 & 114.0 & 3 & 119.0 & 4 \\
\hline Eve* & 110.0 & 2 & 126.5 & 7 & 120.5 & 7 & 113.0 & 1 & 119.0 & 3 \\
\hline Callao & 113.0 & 3 & 123.0 & 4 & 111.5 & 1 & 114.0 & 2 & 112.0 & 1 \\
\hline Nomini & 113.0 & 5 & 119.0 & 2 & 117.0 & 4 & 115.0 & 4 & 119.0 & 5 \\
\hline Doyce* & 113.0 & 4 & 128.5 & 9 & 117.0 & 5 & 115.5 & 7 & 119.0 & 7 \\
\hline Va92-42-46 & 114.0 & 6 & 125.0 & 5 & 115.5 & 3 & 117.0 & 9 & 119.0 & 9 \\
\hline Price & 116.0 & 7 & 131.0 & 10 & 120.5 & 8 & 115.0 & 5 & 119.0 & 6 \\
\hline Wysor & 117.0 & 8 & 127.5 & 8 & 119.5 & 6 & 116.0 & 8 & 119.0 & 8 \\
\hline Dan* & 118.0 & 9 & 121.0 & 3 & 123.5 & 9 & 115.0 & 6 & 121.0 & 10 \\
\hline Thoroughbred & 119.0 & 10 & 125.0 & 6 & 124.0 & 10 & 117.0 & 10 & 118.0 & 2 \\
\hline Standard error & 1.0 & $\ldots$ & 3.3 & $\ldots$ & 2.2 & $\ldots$ & 0.5 & $\ldots$ & 1.0 & $\ldots$ \\
\hline \multicolumn{11}{|c|}{ FHB incidence (\%) } \\
\hline Eve* & 40.0 & 1 & 45.0 & 1 & 35.0 & 2 & 10.0 & 3 & 7.5 & 3 \\
\hline Barsoy & 45.0 & 2 & 65.0 & 6 & 95.0 & 6 & 27.5 & 8 & 5.0 & 2 \\
\hline Thoroughbred & 50.0 & 4 & 45.0 & 2 & 65.0 & 4 & 7.5 & 1 & 17.5 & 6 \\
\hline Nomini & 50.0 & 3 & 75.0 & 8 & 100.0 & 9 & 15.0 & 5 & 30.0 & 9 \\
\hline Dan* & 55.0 & 5 & 65.0 & 7 & 30.0 & 1 & 20.0 & 6 & 1.0 & 1 \\
\hline Wysor & 60.0 & 7 & 50.0 & 3 & 100.0 & 8 & 7.5 & 2 & 17.5 & 7 \\
\hline Va92-42-46 & 60.0 & 6 & 85.0 & 10 & 100.0 & 10 & 10.0 & 4 & 30.0 & 8 \\
\hline Price & 65.0 & 9 & 55.0 & 5 & 90.0 & 5 & 45.0 & 9 & 15.0 & 5 \\
\hline Callao & 65.0 & 8 & 75.0 & 9 & 95.0 & 7 & 20.0 & 7 & 60.0 & 10 \\
\hline Doyce* & 70.0 & 10 & 50.0 & 4 & 55.0 & 3 & 92.5 & 10 & 11.0 & 4 \\
\hline Standard error & 10.0 & $\ldots$ & 11.9 & $\ldots$ & 14.3 & $\ldots$ & 7.3 & $\ldots$ & 11.4 & $\ldots$ \\
\hline \multicolumn{11}{|l|}{ FHB index $(\%)$} \\
\hline Dan* & 2.7 & 1 & 13.2 & 5 & 14.8 & 3 & 4.5 & 7 & 0.1 & 1 \\
\hline Eve* & 3.0 & 2 & 13.4 & 6 & 5.0 & 1 & 1.3 & 3 & 1.1 & 4 \\
\hline Thoroughbred & 3.5 & 3 & 5.2 & 1 & 12.3 & 2 & 1.0 & 2 & 3.5 & 7 \\
\hline Va92-42-46 & 4.0 & 4 & 21.2 & 9 & 90.5 & 10 & 2.3 & 4 & 4.0 & 8 \\
\hline Wysor & 4.2 & 5 & 5.3 & 2 & 78.0 & 9 & 0.9 & 1 & 2.4 & 6 \\
\hline Nomini & 4.2 & 6 & 24.2 & 10 & 72.0 & 8 & 3.8 & 5 & 6.0 & 9 \\
\hline Callao & 4.3 & 7 & 16.6 & 7 & 55.0 & 7 & 4.0 & 6 & 10.5 & 10 \\
\hline Barsoy & 4.9 & 8 & 21.1 & 8 & 50.0 & 6 & 4.8 & 8 & 1.0 & 3 \\
\hline Price & 5.5 & 9 & 12.9 & 4 & 43.3 & 5 & 11.5 & 9 & 1.8 & 5 \\
\hline Doyce* & 9.4 & 10 & 8.7 & 3 & 15.5 & 4 & 35.3 & 10 & 0.6 & 2 \\
\hline Standard error & 2.4 & $\ldots$ & 6.6 & $\ldots$ & 13.3 & $\ldots$ & 4.4 & $\ldots$ & 2.6 & $\ldots$ \\
\hline \multicolumn{11}{|l|}{$\mathrm{DON}(\mathrm{ppm})^{\mathrm{c}}$} \\
\hline Eve* & 0.3 & 1 & 1.1 & 6 & 0.8 & 9 & 0.5 & 1 & 0.7 & 2 \\
\hline Barsoy & 0.5 & 2 & 0.5 & 1 & 0.2 & 4 & 2.1 & 6 & 0.8 & 4 \\
\hline Nomini & 0.7 & 3 & 0.7 & 3 & 0.6 & 8 & 2.5 & 7 & 1.0 & 7 \\
\hline Dan* & 0.9 & 4 & 1.6 & 9 & 0.0 & 1 & 0.6 & 4 & 0.5 & 1 \\
\hline Va92-42-46 & 1.0 & 5 & 0.5 & 2 & 0.1 & 3 & 1.4 & 5 & 0.7 & 3 \\
\hline Doyce* & 1.2 & 6 & 2.4 & 10 & 1.7 & 10 & 0.6 & 2 & 0.9 & 5 \\
\hline Callao & 1.4 & 7 & 1.5 & 8 & 0.1 & 2 & 0.6 & 3 & 2.3 & 10 \\
\hline Wysor & 2.4 & 8 & 0.8 & 4 & 0.2 & 5 & 2.5 & 8 & 0.9 & 6 \\
\hline Price & 3.1 & 9 & 1.0 & 5 & 0.3 & 7 & 5.8 & 9 & 2.0 & 9 \\
\hline Thoroughbred & 4.4 & 10 & 1.2 & 7 & 0.3 & 6 & 6.0 & 10 & 1.9 & 8 \\
\hline Standard error & - & $\ldots$ & 0.5 & $\ldots$ & 0.3 & $\ldots$ & 1.8 & $\ldots$ & - & $\ldots$ \\
\hline
\end{tabular}

${ }^{a}$ Barely cultivars or lines followed by an asterisk (*) indicate a hulless genotype and those without an asterisk indicate a hulled genotype.

${ }^{\mathrm{b}}$ Flowering date $(\mathrm{FD})=$ days from 1 January and indicates barley heads at $50 \%$ anthesis.

${ }^{c}$ Standard error for deoxynivalenol (DON) in 2006 and 2010 was not reported due to lack of degrees of freedom. 
were shown to have lower levels of disease and DON compared with susceptible genotypes (22). Barley has natural type II resistance to FHB (14) and, therefore, differences in FHB disease between genotypes is likely due to differences in type I resistance.

Significant differences among replicates in FHB incidence or FHB index may be due to differences in plot location of replicate genotypes within the field. For example, if one replicate of a particular barley genotype is close in proximity to a plot with high disease, movement of inoculum from adjacent plots may explain differences in disease ratings between replicates (16). Furthermore, orientation of the misting system and background inocula naturally present in the field (and different from the artificially applied inoculum in this study) may help explain some of the differences among replicates. Aggressiveness of Fusarium spp. can vary strain to strain and may depend on the mycotoxin potential of the strains used for inoculation (21); therefore, plots of susceptible barley genotypes may be exposed to different background inoculum sources (in addition to the artificial inoculum applied to the plots) and could explain variable disease ratings and DON levels.

The mean DON concentration was lowest in 2008, whereas FHB incidence and index were highest in the same year (Table 2). The 3 years with the lowest DON levels (2007 to 2009) did not correlate with FHB incidence or index (Table 4). Differences in levels of resistance between genotypes of wheat have previously been shown to impact DON accumulation (21). Associations between FHB and DON may not be evident when susceptible and moderately susceptible cultivars are analyzed for correlations in contrast to analyses that incorporate a range of susceptible and resistant genotypes $(1,2)$. Therefore, the population of barley genotypes within each year may play an important role in determining the association between DON concentration and FHB.

FHB and DON are thought to be positively correlated in wheat (1). For instance, 116 cultivars and breeding lines in greenhouse tests and 33 cultivars in field tests were evaluated in 1997 for FHB resistance, and a positive correlation was found between FHB and DON (2). In a meta-analysis of 163 studies involving FHB and DON accumulation in wheat, correlation coefficients ranged from -0.58 to 0.99 and more than $65 \%$ of correlation coefficients were greater than 0.50 (25). This study revealed that FHB and DON accumulation are generally correlated yet there are examples of negative associations (25). Cases of negative associations may be explained by the unintentional removal of small and lightweight kernels from FHB-infected spikes during threshing (1). Loss of lightweight kernels with high DON would not be included during DON quantification, thereby impacting associations with high ratings of FHB incidence and FHB index (1). However, in this study, preventative measures were taken to reduce the loss of infected kernels by reducing the strength of the blower on the combine during harvest. Infection levels of $F$. graminearum on hulled versus hulless genotypes did not vary significantly in previous work (18). However, a large proportion of DON has been shown to accumulate in the hull and, therefore, less DON may be present in harvested hulless barley grain versus the preharvested grain, as previously described (18). In our analysis, weak negative associations between FHB and DON were seen from 2007 to 2009; however, they were not significant (Table 4). Significant negative correlations were observed between FD and FHB incidence and index (Table 4). This is consistent with previous studies reporting negative correlations between heading date and FHB (6). However, because spray inoculation was used in this study, weather conditions (34) likely played a more important role in determining differences between FD and FHB than the timing of head emergence.

Efforts within the Virginia Tech winter barley breeding program are currently focused on further characterizing hulled and hulless genotypes for FHB resistance. Significant differences in FHB and DON resistance were observed among genotypes that were selected to evaluate resistance stability across years (Table 5). Factors such as variable weather conditions and plot locations within the field, as described previously in this article, may contribute to fluctuations of FHB resistance and DON accumulation across years for individual genotypes; however, stable genotypes were identified. Thoroughbred (hulled) barley was identified as consistently being resistant to FHB and Eve (hulless) barley was identified as consistently resistant to both FHB and DON accumulation (Table 6). Callao (hulled) barley was identified in this study as consistently being susceptible to FHB and accumulating high levels of DON (Table 6). This study sets the foundation for further work and characterization of resistance in Virginia hulled and hulless barley. Genotypes with indications of resistance and susceptibility from this data will be further evaluated during the following growing seasons. Future efforts will be focused on the development of populations in FHB nurseries to map QTLs contributing to FHB and DON resistance in both hulled and hulless barley genotypes and to develop hulled and hulless cultivars with improved FHB resistance.

\section{Acknowledgments}

P. A. Khatibi and G. Berger contributed equally to this work and should be considered co-first authors. For correspondence about the specific genotypes in this work, please contact C. A. Griffey. For correspondence about the DON testing in this work, please contact D. G. Schmale, III. This work was supported in part by grants to D. G. Schmale, III from the Virginia Small Grains Board (10278306) and the U.S. Wheat and Barley Scab Initiative (07185403), and to C. A. Griffey from the USWBSI (59-0790-4-102). The conclusions presented here are those of the authors and do not necessarily reflect the views of the United States Department of Agriculture or the Virginia Small Grains Board.

\section{Literature Cited}

1. Bai, G., and Shaner, G. 2004. Management and resistance in wheat and barley to Fusarium head blight. Annu. Rev. Phytopathol. 42:135-161.

2. Bai, G. H., Plattner, R., Desjardins, A. E., and Kolb, F. 2001. Resistance to Fusarium head blight and deoxynivalenol accumulation in wheat. Plant Breed. 120:1-6.

3. Boyd, C., Horsley, R., and Kleinhofs, A. 2007. Barley chromosome 2(2H) bin 10 Fusarium head blight resistance QTL: mapping and development of isolines. In: United States Wheat and Barley Scab Initiative, Kansas City, MO.

4. Canci, P., Nduulu, L., Dillmacky, R., Muehlbauer, G. J., and Rasmusson, D. C. 2003. Genetic relationships between kernel discoloration and grain protein concentration in barley. Crop Sci. 43:1671-1679.

5. Chen, J., Griffey, C. A., Saghai Maroof, M. A., Stromberg, E. L., Biyashev, R. M., Zhao, W., Chappell, M. R., Pridgen, T. H., Dong, Y., and Zeng, Z. 2006. Validation of two major quantitative trait loci for Fusarium head blight resistance in Chinese wheat line W14. Plant Breed. 125:99-101.

6. Choo, T. M., Martin, R. A., Ho, K. M., Shen, Q. Q., Fedak, G., Savard, M. Voldeng, H., Falk, D. E., Etienne, M., and Sparry, E. 2004. Fusarium head blight and deoxynivalenol accumulation of barley in eastern Canada: cultivar response and correlation analysis. Plant Dis. 88:837-844.

7. Choo, T. M., Vigier, B., Shen, Q. Q., Martin, R. A., Ho, K. M., and Savard, M. 2004. Barley traits associated with resistance to Fusarium head blight and deoxynivalenol accumulation. Phytopathology 94:1145-1150.

8. Cowger, C., and Sutton, A. L. 2005. The southeastern U.S. Fusarium head blight epidemic of 2003. Plant Health Progress.

9. Dahleen, L. S., Okubara, P. A., and Blechl, A. E. 2001. Transgenic approaches to combat Fusarium head blight in wheat and barley. Crop Sci. 41:621-637.

10. de la Pena, R. C., Smith, K. P., Capettini, F., Muehlbauer, G. J., GalloMeagher, M., Dill-Macky, R., Somers, D. A., and Rasmusson, D. C. 1999. Quantitative trait loci associated with resistance to Fusarium head blight and kernel discoloration in barley. Theor. Appl. Genet. 99:561-569.

11. Del Ponte, E. M., Fernandes, J. M., and Bergstrom, G. C. 2003. Fusarium head blight and deoxynivalenol accumulation in wheat inoculated at developmental stages from flowering through grain maturation. In: National Fusarium Head Blight Forum Proceedings. Cornell University, Bloomington, MN.

12. Goswami, R. S., and Kistler, H. C. 2004. Heading for disaster: Fusarium graminearum on cereal crops. Mol. Plant Pathol. 5:515-525.

13. Goswami, R. S., and Kistler, H. C. 2005. Pathogenicity and in planta mycotoxin accumulation among members of the Fusarium graminearum species complex on wheat and rice. Phytopathology 95:1397-1404

14. Jansen, C., von Wettstein, D., Schafer, W., Kogel, K. H., Felk, A., an Maier, F. J. 2005. Infection patterns in barley and wheat spikes inoculated with wild-type and trichodiene synthase gene disrupted Fusarium graminearum. Proc. Natl. Acad. Sci. USA 102:16892-16897.

15. Kang, Z., and Buchenauer, H. 2000. Ultrastructural and cytochemical studies on cellulose, xylan and pectin degradation in wheat spikes infected by Fusarium culmorum. J. Phytopathol. 148:263-275.

16. Keller, M. D., Waxman, K. D., Bergstrom, G. C., and Schmale, D. G., III 2010. Local distance of wheat spike infection by released clones of Gibber- 
ella zeae disseminated from infested corn residue. Plant Dis. 94:1151-1155.

17. Lagana, A., Curini, R., D’Ascenzo, G., De Leva, I., Faberi, A., and Pastorini, E. 2003. Liquid chromatography/tandem mass spectrometry for the identification and determination of trichothecenes in maize. Rapid Commun. Mass Spectrom. 17:1037-1043.

18. Legzdina, L., and Buerstmayr, H. 2004. Comparison of infection with Fusarium head blight and accumulation of mycotoxins in grain of hulless and covered barley. Cereal Sci. 40:61-67.

19. McLaughlin, C. S., Vaughan, M. H., Campbell, I. M., Wei, C. M., Stafford, M. E., and Hansen, B. S. 1977. Inhibition of protein synthesis by trichothecenes. Pages 263-273 in: Mycotoxins in Human and Animal Health J. V. Rodericks, C. W. Hesseltine, and M. A. Mehlman, eds. Pathotox, Park Forest, IL.

20. McMullen, M., Jones, R., and Gallenberg, D. 1997. Scab of wheat and barley: a re-emerging disease of devastating impact. Plant Dis. 81:13401348.

21. Mesterhazy, A. 2002. Role of deoxynivalenol in aggressiveness of Fusarium graminearum and F. culmorum and in resistance to Fusarium head blight. Eur. J. Plant Pathol. 108:675-684.

22. Mesterhazy, A., Bartok, T., Mirocha, C. G., and Komoroczy, R. 1999. Nature of wheat resistance to Fusarium head blight and the role of deoxynivalenol for breeding. Plant Breed. 118:97-110.

23. Mirocha, C. J., Xie, W., Xu, Y., Wilcoxson, R. D., Woodward, R. P., Etebarian, R. H., and Behele, G. 1994. Production of trichothecene mycotoxins by Fusarium graminearum and Fusarium culmorum on barley and wheat. Mycopathologia 128:19-23.

24. Parry, D., Jenkinson, P., and McLeod, L. 1995. Fusarium ear blight (scab) in small grain cereals-a review. Plant Pathol. 44:207-238.
25. Paul, P. A., Lipps, P. E., and Madden, L. V. 2005. Relationship between visual estimates of Fusarium head blight intensity and deoxynivalenol accumulation in harvested wheat grain: a meta-analysis. Ecol. Epidemiol. 95:1225-1236

26. Pestka, J. J., and Smolinski, A. T. 2005. Deoxynivalenol: toxicology and potential effects on humans. J. Toxicol. Environ Health B Crit. Rev. 8:3969.

27. Rudd, J. C., Horsley, R. D., McKendry, A. L., and Elias, E. M. 2001. Host plant resistance genes for Fusarium head blight. Crop Sci. 41:620-627.

28. Schroeder, H. W., and Christensen, J. J. 1963. Factors affecting resistance of wheat to scab by Gibberella zeae. Phytopathology 53:831-838.

29. Steffenson, B. 1998. Fusarium head blight of barley: epidemics, impact, and breeding for resistance. Tech 35:177-184.

30. Tacke, B. K., and Casper, H. H. 1996. Determination of deoxynivalenol in wheat, barley, and malt by column cleanup and gas chromatography with electron capture detection. J. AOAC Int. 79:472-475.

31. Taketa, S., Amano, S., Tsujino, Y., Sato, T., Saisho, D., Kakeda, K., Nomura, M., Suzuki, T., Matsumoto, T., Sato, K., Kanamori, H., Kawasaki, S. and Takeda, K. 2008. Barley grain with adhering hulls is controlled by an ERF family transcription factor gene regulating a lipid biosynthesis pathway. Proc. Natl. Acad. Sci. USA 105:4062-4067.

32. Tiapo, N. M. 2001. Economic impacts of Fusarium head blight in wheat and barley: 1998-2000. North Dakota State University, Fargo, ND.

33. Urrea, C., Horsley, R., Steffenson, B., and Schwarz, P. 2002. Heritability of Fusarium head blight resistance and deoxynivalenol accumulation from barley accession CIho 4196. Crop Sci. 42:1404-1408.

34. Xu, X. 2003. Effects of environmental conditions on the development of Fusarium ear blight. Eur. J. Plant Pathol. 109:683-689. 